\title{
Uma análise da percepção da biblioteca da Pontifícia Universidade Católica de São Paulo pelos alunos da sua Faculdade de Economia e Administração
}

Mauro Maia Laruccia

\begin{abstract}
Bacharel em Administração de Empresas pela Pontifícia Universidade Católica de São Paulo. Mestre em Administração pela Pontifícia Universidade Católica de São Paulo.Doutor em Comunicação e Semiótica pela Pontifícia Universidade Católica de São Paulo Pós-doutor em Análise do Ethos discursivo da inovação e sustentabilidade nas organizações
\end{abstract}

http://dx.doi.org/10.1590/1981-5344/2036

Este trabalho tem como objetivo identificar a percepção dos alunos de graduação da Faculdade de Economia e Administração da Pontifícia Universidade Católica de São Paulo (FEA-PUC) com relação à infraestrutura e, em especial, a biblioteca. Utilizou-se o método survey de pesquisa para levantar os dados e abordagem quantitativo-qualitativa. Os resultados demonstraram que a biblioteca central da PUC atende às expectativas dos alunos da Instituição na avaliação quantitativa $(N=450)$, mas na avaliação qualitativa $(N=18)$, o acervo da biblioteca relacionado aos cursos de Administração, Ciências Econômicas, Ciências Contábeis e Atuariais oferece parcialmente suporte as atividades de ensino, pesquisa ou extensão.

Palavras-chave: Biblioteca universitária; Estudo de usuário; Qualidade; Acervo; Infraestrutura. 


\title{
An analysis about perception of the Pontifical Catholic University of São Paulo Central Library by students of its Faculty of Economics and Administration
}

\begin{abstract}
This study aims to identify the perception of undergraduate students of the Faculty of Economics and Administration with respect to infrastructure and, in particular, the library. We used the survey research method to collect data and quantitative-qualitative approach. The results showed that the central library of the Pontifical Catholic University of São Paulo (PUC-SP) meets the expectations of students of the institution in the quantitative assessment $(N=450)$, but the qualitative evaluation $(N=18)$, the assets of PUC-SP library related to courses in Administration, Economics, Accounting and Actuarial Sciences offers partially support the activities of teaching, research and extension.
\end{abstract}

Keywords: University library; Quality; Collection; Infrastructure; User study.

Recebido em 07.07.2014 Aceito em 12.11.2015

\section{Introdução}

A presente investigação tem como objetivo estudar o impacto da percepção da biblioteca no contexto da infraestrutura relacionado à qualidade e excelência na Pontifícia Universidade Católica de São Paulo, especificamente pelos alunos dos cursos de graduação da Faculdade de Economia e Administração (FEA-PUC).

$O$ estudo da qualidade do ensino superior terá objetivo secundário nesta investigação, uma vez que este fator tem uma ligação direta com a satisfação dos alunos do ensino superior. Devido à complexidade do fator qualidade, este terá de ser analisado separadamente da satisfação, pois isso irá permitir identificar quais são as diferentes dimensões que o fator qualidade comporta.

O ensino superior no Brasil vem sofrendo diversas mudanças (LARUCCIA, 2011). As causas para a satisfação dos alunos que já estão no ensino superior são a satisfação com o curso, o prestígio acadêmico, a infraestrutura e sua biblioteca, a grife relacionada ao ensino, e a empregabilidade (AITKEN, 1982).

O desenvolvimento das bibliotecas está relacionado com o aumento informacional e à evolução tecnológica obrigam-nas a rever a forma de atendimento dos seus usuários e a facilitar o acesso ao conteúdo 
informacional (LARUCCIA; COSMANO; NARDI, 2012). Além disso, melhorar a qualidade dos serviços nas bibliotecas universitárias tem sido uma preocupação frequente. Silva (2000) sugere que os objetivos organizacionais, especificamente os operativos, podem influenciar a percepção de qualidade percebida pelos alunos.

Vergueiro e Carvalho (2001) sugerem medidas que devem ser desenvolvidas pelas bibliotecas universitárias para o aprimoramento do estudo e a melhoria da qualidade dos serviços/atendimento prestados aos clientes das instituições de ensino superior.

A busca pela excelência é uma preocupação frequente dos administradores para atingirem os objetivos das organizações que presidem de forma eficiente. (VANTI, 1999). Peters e Waterman propõem uma abordagem Darwiniana que deve ser adotada em busca da excelência. É o ensaio-erro visto como ingrediente número um em que é melhor fazer algo errado do que não fazer nada: não devemos ter medo de fazer algo errado, pois numa próxima tentativa poderemos aprender com erros passados e melhorar. Desta forma, a excelência pode ser alcançada em etapas sucessivas (PETERS; WATERMAN, 2012).

Ao longo dos anos em que o tema da qualidade foi abordado, diversos modelos foram elaborados tendo em vista aprofundar o seu conhecimento. Atualmente dois dos modelos mais utilizados para o estudo da qualidade são: o nórdico da qualidade (GRÖNROOS, 1982); e o modelo SERVQUAL (PARASURAMAN; ZEITHAML; BERRY, 1985). Ambas as abordagens tem como base o modelo da desconfirmação realçando a relação que existe entre a variável qualidade e satisfação (OLIVER, 1977).

Lima e Duarte (2012) destacam que a qualidade nos serviços de informação é um fator imprescindível para gerar satisfação de seus clientes. Em seu estudo utilizando a abordagem SERVQUAL concluíram que é preciso melhorar a confiabilidade, responsabilidade, segurança, empatia e tangibilidade.

Com relação à qualidade dos serviços prestados pelas bibliotecas (RODRIGUES; CASTRO; SANTOS, 2013) afirmam que a liderança; o sistema de informações sobre qualidade em serviços; a estratégia de serviços; o nível de comprometimento dos colaboradores; a estratégia tecnológica; os níveis de confiabilidade, surpresa, recuperação e integridade afetam e devem ser analisados pela equipe de gestão continuamente. Além disso, Alentejo e Baptista (2012) destacam que a importância de conhecer os aspectos teóricos relacionados com qualidade para contribuir na melhoria das bibliotecas.

O conhecimento derivado dos estudos da qualidade e da satisfação foi aprofundado ao longo dos anos e permitiu extrapolar, e mesmo estudar diretamente, diferentes setores de serviços, como uma biblioteca (KASPER; HELSDINGEN; GABBOTT, 2006). 


\section{A Biblioteca da PUC/SP}

A Biblioteca Nadir Gouvêa Kfouri, da PUC-SP, ocupa 4.300m², destinando $60 \%$ para armazenamento do acervo e serviços técnicos e $40 \%$ para atendimento ao usuário, disponibilizando mais de 600 lugares para estudo.

Dispõe de espaço para exposição e eventos; duas cabines de estudo; quatro colmeias para projeção de vídeo e DVD; e um auditório com 40 lugares. A Biblioteca conta, ainda, com o acervo de aproximadamente: 180.291 volumes de livros; 16.780 títulos de teses e dissertações; 4.848 títulos de periódicos; 5.980 títulos de fita de vídeo; 183 títulos de DVDs; 200 títulos em microfichas e microfilmes; 333 títulos de CD-ROM; 15 títulos de softwares; 28.425 títulos de slides; e 1.806 miscelâneas (apostilas, TCCs, seminários, etc.).

A biblioteca atende às áreas de Educação, Filosofia, Psicologia, Direito, Economia, Administração, História, Geografia, Fonoaudiologia, Serviço Social, Língua e Literatura, Linguística, Comunicações, Artes, Ciências Sociais, Ciências Contábeis e Atuariais, Relações Internacionais e Turismo.

Fazem parte, ainda, da estrutura da biblioteca: (a) Hemeroteca: acervo formado de jornais e revistas da grande imprensa, jornais alternativos. (b) Videoteca: acervo formado de fitas de vídeo VHS e DVDs educativos e de ficção. Promove eventos, apoia e incentiva projetos para produção de vídeos e registra as principais palestras da Universidade. (d) Multimídia: Acesso disponibilizado às bases de dados em CD-ROM e DVD (PONTIFICIA UNIVERSIDADE CATÓLICA DE SÃO PAULO, 2012).

\section{Procedimentos metodológicos}

Com relação à metodologia da pesquisa, foi dividida em três categorias de tipologia de pesquisa: quanto aos objetivos, foi utilizada a pesquisa exploratória e descritiva; quanto aos procedimentos, foi utilizada o levantamento de dados ou survey para os dados primários; e quanto à abordagem do problema, trata-se de uma pesquisa quali-quanti (DE VAUS, 2002; MALHOTRA, 2008; MCDANIEL; GATS, 2003; RAUPP; BEUREN, 2006; REA; PARKER, 2000).

O questionário conteve quatro partes para estudar a percepção dos alunos da FEA/PUC, sendo a primeira relativa à qualidade, a segunda aos preços, a terceira em relação à satisfação geral e a quarta parte em relação aos dados pessoais. Para todo o questionário (exceto as perguntas relativas à quarta parte - dados pessoais) foi utilizada escala de Likert com classificações entre 1 e 7, sendo que o valor mais baixo representa "Discordo Totalmente" e o valor mais elevado representa "Concordo Totalmente".

Foi realizado um pré-teste do questionário com duas turmas de Administração do período noturno em agosto foi ajustado o questionário 
eletrônico, alterando a escala de 7 itens para 5 itens antes de enviar para os alunos da FEA/PUC.

Os dados primários foram obtidos por meio de questionário aplicado para 4760 alunos da FEA/PUC no segundo semestre de 2013, o que representava toda a população de alunos, conforme relação enviada pela Secretaria. A amostra obtida foi 450 respondentes $(N=450)$, apenas (um) respondente recusou-se a responder o questionário. A amostra obtida $(\mathrm{N}=450)$ apresenta nível de confiança de $95 \%$ com $2 \%$ de precisão ou $99 \%$ de confiança com $3 \%$ de precisão para uma população de 4760 alunos.

A amostra estudada, conforme a Tabela 1 revelou consistência interna aceitável (Alfa de Cronbach de 0,937 e, Alfa de Cronbach com base em itens padronizados 0,939 respetivamente para as questões) (CORRAR; PAULO; DIAS FILHO, 2007). Os resultados obtidos em planilha Excel foram importados para SPSS/PAWS.

Tabela 1 - Análise do Alfa de Cronbach por item pesquisado

\begin{tabular}{c|l|c}
\hline Itens & \multicolumn{1}{|c}{ Variáveis pesquisadas } & $\begin{array}{c}\text { Alfa de } \\
\text { Cronbach se } \\
\text { o item for } \\
\text { excluído }\end{array}$ \\
\hline \hline 1 & Tangibilidade: Possui infraestrutura adequada ao número de alunos & 0,941 \\
2 & Tangibilidade: Possui material de apoio adequado & 0,940 \\
3 & Tangibilidade: Possui biblioteca com livros e base de dados & 0,942 \\
& atualizados & \\
\hline
\end{tabular}

Fonte: Dados da pesquisa.

A participação dos respondentes no estudo pelos estudantes foi voluntária, mediante a leitura e assinatura de um Termo de Consentimento Livre e Esclarecido. Neste termo foi assegurado o sigilo da fonte e das informações, bem como, a inexistência de quaisquer prejuízos para eles, caso não quiserem participar ou desistirem de fazê-lo em qualquer momento.

\section{Análise e discussão dos resultados}

O perfil dos respondentes apresentou as seguintes características: homens (58\%), de 18 a 25 anos (78\%) do curso de Administração $(60 \%)$, do 40 período (14\%), período noturno (79\%), estagiários (37\%), de atividades de serviços (44\%), em empresas com mais de 500 funcionários (46\%), em empresas de grande porte (52\%).

No contexto da avaliação superior incorporada pelas instituições de ensino superior e regulada pelo Instituto Nacional de Estudos e Pesquisas Educacionais Anísio Teixeira (INEP), o resultado é uma mudança cultural das IES em relação às avaliações realizadas por parte do MEC traduzido pela intensificação da capacitação docente, contratação de mestres e doutores, investimentos em infraestrutura, laboratórios, biblioteca etc. Nas bibliotecas, as mudanças têm demandado investimentos constantes das IES, em função de políticas internas, ou, na 
sua maioria, por pressão dos processos avaliativos, em que condições da biblioteca têm grande peso na pontuação do item infraestrutura.

Tabela 2 - Resultado geral da percepção dos alunos

\begin{tabular}{c|l|c}
\hline Itens & \multicolumn{1}{|c|}{ Variáveis pesquisadas } & Média \\
\hline \hline 1 & Tangibilidade: Possui infraestrutura adequada ao número de alunos & $2(29 \%)$ \\
2 & Tangibilidade: Possui material de apoio adequado & $2(33 \%)$ \\
3 & Tangibilidade: Possui biblioteca com livros e base de dados atualizados & $4(36 \%)$ \\
\hline
\end{tabular}

Fonte: Dados da pesquisa.

Podemos observar inicialmente, na Tabela 2, que a dimensão tangibilidade, em uma escala de 1 a 5, de forma geral a FEA-PUC obteve avaliação abaixo da média na infraestrutura e no material de apoio, apenas obteve avaliação positiva na biblioteca, ocorrendo divergência. Podemos inferir que a falta de infraestrutura e de material de apoio oferecido pela faculdade não afetou a imagem da biblioteca.

Acreditamos que fenômeno ocorreu pelo fato de a percepção da qualidade não é algo nítido. Baseia-se em critérios objetivos e subjetivos. Além disso, gerenciar serviços é diferente de gerenciar produção de bens, pois serviços são intangíveis, ou seja, não podem ser possuídos, mas vivenciados, e por isso são de difícil padronização.

Os consumidores, neste caso alunos, escolhem serviços comparando as percepções do serviço percebido com o esperado, o que é chamado de qualidade de serviço percebida. Bons resultados na qualidade percebida são obtidos quando os serviços recebidos ou experimentados atendem às expectativas do cliente (GRÖNROOS, 1979; 1995). É atribuída à qualidade de serviços a discrepância que existe entre as expectativas e as percepções sobre o serviço esperado (ZEITHAML; PARASURAMAN; BERRY, 1990)

Salientamos, ainda, com base nos resultados avaliativos da CPA da PUC-SP, está previsto ouvir os segmentos universitários quanto aos aspectos da infraestrutura que interferem na prática docente para aprimorar as atividades da Dimensão Ensino na Universidade (PONTIFICIA...., 2012).

$\mathrm{Na}$ análise da resposta qualitativa (STRAUSS; CORBIN, 2008) referente à pergunta aberta "sobre o que falta para a FEA/PUC ser excelente", foram separados os elogios das críticas e sugestões, para reflexão e realizações de ações futuras que venham atender na totalidade ou em partes às solicitações dos usuários, que muito contribuíram com suas colocações.

Responderam a esta questão 315 dos 450 alunos, isto é 70\% dos participantes da pesquisa responderam sobre os serviços oferecidos pela FEA e pelo curso. Desses 315 respondentes, 18 emitiram opiniões relacionadas com a biblioteca. As respostas foram transcritas de acordo com o que responderam os alunos, não sendo, de forma alguma, alterado o conteúdo. Foram mantidos os erros de português, tamanho e formato da fonte, procurou-se manter a originalidade dos escritos. 
As respostas dos alunos 18, 32, 90, 91, 124, 139, 353, 438 e 448 foram destacadas, por apontarem os elogios, críticas ou sugestões da biblioteca da PUC-SP.

A biblioteca não tem livros de ciências atuariais (Aluno 18).

Instrumentos que podem ser usados em salas de aulas e uma biblioteca renovada são de grande importância também (Aluno 32).

Atualização dos livros na biblioteca e maior diversidade de títulos (Aluno 90).

A Biblioteca precisa de livros atualizados e pelo menos um livro de cada tipo que os profs. utilizam (para Consulta Local) é comum os profs. solicitarem livros que não há NENHUM para Consulta Local na Biblioteca, obrigando assim que o aluno compre o livro se quiser se preparar para as provas (Aluno 91).

Falta mais infraestrutura na faculdade, salas de estudo separadas da biblioteca, aonde é permitida a conversa, atualização dos equipamentos da PUC (Aluno 92).

A biblioteca é limitada e alguns livros indicados pelos professores nós não possuímos (Aluno 124).

O curso deveria ter um caráter mais autônomo e de pesquisa para o aluno e ser menos hierarquizado. Boa parte do meu aprendizado foi na monografia enquanto passava boa parte do tempo pesquisando na biblioteca (Aluno 128).

Disponibilizar mais computadores na biblioteca com programas de pesquisa liberados (Aluno 139).

Uma biblioteca melhor estruturada e mais atualizada (Aluno 353).

A biblioteca possui poucos exemplares dos livros e disponibiliza todos para locação, então os alunos tem dificuldade em consultar alguns livros, desse modo os professores tem dificuldade em exigir leitura dos alunos, o que é muito importante para a formação dos mesmos (Aluno 438). 
A biblioteca é muito boa, contudo há alguns livros que são usados em diversas disciplinas e cursos e que possuem poucos exemplares não conseguindo atender à demanda (Aluno 448).

As respostas obtidas pelos alunos, a exceção do aluno 448, vão ao encontro da essência das bibliotecas universitárias que tem por missão oferecer suporte de suas atividades; sejam elas de ensino, pesquisa ou extensão. Desta forma, devemos priorizar recursos informacionais, infraestrutura e serviços adequados para a(s) atividade(s) definida(s) pela comunidade acadêmica.

Atualmente, diversas questões, como qualidade nas bibliotecas de IES e indicadores de qualidade, foram apresentadas em publicações e eventos científicos (OLIVEIRA, 2002). A autora afirma que vários trabalhos alertam para a necessidade de estabelecer a filosofia da qualidade nos serviços de informação como busca de uma gestão eficaz de recursos nas bibliotecas universitárias.

Mesmo com a percepção de qualidade da biblioteca da PUC na avaliação quantitativa, a avaliação qualitativa revela que os padrões de qualidade do MEC não considera a função pedagógica.

[...], pois a biblioteca constitui-se em uma unidade de análise no item infraestrutura e equipamentos dos cursos, o que demonstra sua avaliação somente como instalação e não com uma função acadêmica e pedagógica. São considerados os seguintes indicadores: acervo, área física, organização do acervo, formas de acesso, recursos humanos, informatização, produtos e serviços e política de atualização e expansão (OLIVEIRA, 2002, p. 212).

Nas respostas dos alunos podemos observar, ainda, que o acervo da biblioteca da PUC relacionado aos cursos de Administração, Ciências Econômicas, Ciências Contábeis e Atuariais, entendido como o conjunto de recursos informacionais registrados em qualquer tipo de suporte (impresso, meio eletrônico, imagens, áudio etc.) que compõem a biblioteca apresenta deficiências. Deficiência que podemos hipotetizar como uma utilização atualizada de referencias pelos professores da FEA/PUC que não são incorporadas pela biblioteca na mesma velocidade (ver Aluno 124), talvez por falta de recursos financeiros.

As quantificações e as indicações de bibliografias por parte das comissões de especialistas auxiliam e constituem excelentes referências, mas não podem tornar-se camisa-de-força, incentivando a montagem de bibliotecas para as comissões, totalmente desvinculadas da realidade dos cursos (OLIVEIRA, 2002, p. 214).

Com relação às restrições orçamentárias, a explosão informacional e a carência de espaço físico promoveram a disciplina de desenvolvimento 
de coleções baseadas nas novas mídias e nas tecnologias de informação e comunicação para tornar o desenvolvimento do acervo atual (MATTOS; DIAS, 2009).

\section{Considerações finais}

Devido ao incrível aumento informacional e à evolução tecnológica, reforça-se a necessidade de repensar a melhor maneira de disponibilizar a informação e rever a forma de atuar no atendimento dos usuários, principalmente os alunos, desses ambientes, especialmente para providenciar e facilitar o acesso ao conteúdo informacional com eficiência e eficácia.

Percebe-se que, nos últimos anos, crescem as reflexões em relação às bibliotecas, talvez, devido ao rápido processo de mudança nas áreas científica, tecnológica, econômica, política e social, devendo-se, no entanto, priorizar $o$ acesso à informação, à aprendizagem e ao desenvolvimento intelectual, a fim de apoiar o avanço daqueles que necessitam melhorar a qualidade de seu aprendizado.

O uso da biblioteca como metodologia de ensino-aprendizagem pode ser rica e estimulante. Assim, o trabalho de orientação no uso do acervo, para promover o uso de fontes de informação, juntamente com o estímulo e a implantação de atividades relacionadas com os projetos pedagógicos dos cursos, pode criar uma relação de uso e percepção da importância da biblioteca pelos professores e alunos para estimular 0 interesse pela leitura.

A intenção desta pesquisa foi estudar, especificamente, qual é a percepção dos alunos sobre a qualidade dos serviços oferecidos, e em especial, sobre a percepção da infraestrutura da FEA/PUC com destaque para a biblioteca central.

Foi possível avaliar que a biblioteca da PUC satisfaz às necessidades dos usuários, isto é, os alunos da FEA, quando da avaliação quantitativa, mas, conforme se observou nas respostas qualitativas dos sujeitos pesquisados, ainda cabe apontar a necessidade de se realizar algumas ações de melhoria na biblioteca.

Vale ressaltar, que de acordo com o relatório de gestão da PróReitoria de Planejamento da Universidade, em relação ao PDI -2010-2015, a requalificação da Biblioteca Central deverá ser objeto de execução até 2015 (PONTIFICIA ..., 2012).

Contudo, recomenda-se que, para qualquer tipo de investimento, seja ele tecnológico, humano, manutenção, atualização e modernização do acervo, além de material bibliográfico, e seria importante ouvir os usuários. Como sugestão, poderia ser apresentada à FAPESP ou a outras agências fomento a pesquisa, uma proposta de financiamento para modernizar a biblioteca da PUC-SP.

Importante ainda, para melhorar a percepção dos alunos propagar que a PUC-SP conta, com oito bibliotecas instaladas em diversos campi, que juntas compõem o Sistema de Bibliotecas. Sistema que tem como 
meta desenvolver e disponibilizar à comunidade acadêmica serviços e produtos, que permitam o acesso a recursos informacionais necessários ao desenvolvimento do ensino, pesquisa e extensão. $E$, nesse sentido, objetivam organizar, preservar e disseminar a produção do conhecimento; promover o intercâmbio entre bibliotecas nacionais e internacionais, satisfazendo as necessidades dos usuários; orientar o uso das fontes de informação nos diversos suportes físicos e virtuais e manter acervo consistente e atualizado (PONTIFICIA....-, 2012).

Para concluir, lembramos que a presente pesquisa apresenta algumas limitações, a saber: (a) trata-se de uma investigação empírica, aplicada aos alunos da FEA-PUC-SP, no segundo semestre de 2013. Portanto, não se refere esta pesquisa a qualquer outro período de tempo, outra qualquer entidade, região geográfica ou objeto; (b) os alunos foram convidados a responder questionários específicos, presumindo-se que as respostas obtidas foram dadas efetivamente pelos respondentes, a quem os questionários foram endereçados eletronicamente e expressam suas opiniões. Dessa forma, apenas este conjunto de respostas foi levado em conta; (c) os dados coletados foram analisados e considerados adequados à tipologia ordinal dos dados, pelo que os resultados das análises não levam em conta outras possíveis observações, fora do estudo proposto.

\section{Referências}

AITKEN, N. D. College student performance, satisfaction and retention: specification and estimation of a structural model. Journal of Higher Education, v. 53, n. 1, p. 32-50, 1982. Disponível em: <http://www.jstor.org/stable/1981537>. Acesso em: 11 dez. 2013.

ALENTEJO, E. da S.; BAPTISTA, S. G. A Trajetória da gestão pela qualidade nas bibliotecas brasileiras. Informação \& Informação, v. 17, n. 1 , p. 132-165, 2012.

CORRAR, L.; PAULO, E.; DIAS FILHO, J. M. Análise multivariada para os cursos de administração, ciências contábeis e economia. São Paulo: Atlas, 2007.

DE VAUS, D. A. Surveys in social research. 5. ed. St. Leonards, N.S.W.: Allen \& Unwin, 2002.

GRÖNROOS, C. An applied service marketing theory. European Journal of Marketing, v. 16, n. 7, p. 30-41, 1982. Disponível em: $<$ http://www.emeraldinsight.com/journals. htm?articleid $=852847 \&$ show $=a$ bstract>. Acesso em: 30 dez. 2012.

GRÖNROOS, C. An applied theory for marketing industrial services. Industrial Marketing Management, v. 8, n. 1, p. 45-50, 1979. Disponível em:

<http://www.sciencedirect.com/science/article/pii/0019850179900178>. Acesso em: 30 dez. 2012. 
GRÖNROOS, C. Relationship marketing: the strategy continuum. Journal of the Academy of Marketing Science, v. 23, n. 4, p. 252-254, 1995. Disponível em: <http://www.springerlink.com/index/45376515R77L4H7G.pdf>. Acesso em: 30 dez. 2012.

KASPER, J. D. P.; HELSDINGEN, P. J. C. V.; GABBOTT, M. Services marketing management: a strategic perspective. Chichester, NJ: J. Wiley \& Sons, 2006.

LARUCCIA, M. M. Impacto da universidade corporativa nas organizações. Revista de Administração da Unimep, v. 9, n. 1, p. 146-163, 2011. Disponível

em: <http://regen.com.br/ojs/index.php/regen/article/view/299/461>. Acesso em: 16 out. 2013.

LARUCCIA, M. M.; COSMANO, S. R.; NARDI, R. G. Uma análise da contribuição da biblioteca da Fundacentro na produção científica em segurança e saúde no trabalho. Perspectivas em Ciência da Informação, v. 17, n. 1, p. 185-202, mar. 2012. Disponível em: $<$ http://www.scielo.br/scielo.php?script=sci_arttext\&pid=S141399362012000100011\&lng=pt\&nrm=iso\&tlng=en $>$. Acesso em: 16 out. 2013.

LIMA, D. de F. A. de; DUARTE, E. N. A qualidade nos serviços de informação ao público: Estudo na Unidade de Saúde da Família de Mangabeira, João Pessoa-PB. Biblionline, v. 6, n. esp., p. 92-108, 2011.

MALHOTRA, N. K. Marketing research: an applied orientation. India: Pearson Education India, 2008.

MATTOS, A. M.; DIAS, E. J. W. Desenvolvimento de coleções em bibliotecas universitárias: uma abordagem quantitativa. Perspectivas em Ciência da Informação, v. 14, n. 3, p. 38-60, 12 set. 2009. Disponível em: $<$ http://portaldeperiodicos.eci.ufmg.br/index.php/pci/article/view/214>. Acesso em: 6 mar. 2014.

McDANIEL, C.; GATS, R. Pesquisa de Marketing. São Paulo: Pioneira, 2003.

OLIVEIRA, N. M. A biblioteca das IES e os padrões de qualidade do MEC: uma análise preliminar. Perspectivas em Ciência da Informação, v. 7, n. 2, p. 207-221, 2002. Disponível em: <http://portaldeperiodicos.eci.ufmg.br/index.php/pci/article/view/409>. Acesso em: 6 mar. 2014.

OLIVER, R. L. Effect of expectation and disconfirmation on postexposure product evaluations: An alternative interpretation. Journal of Applied Psychology, v. 62, n. 4, p. 480-486, 1977. Disponível em: <http://content.apa.org/journals/apl/62/4/480>. Acesso em: 1 abr. 2012. 
PARASURAMAN, A.; ZEITHAML, V. A; BERRY, L. L. A conceptual model of service quality and its implications for future research. Journal of Marketing, v. 49, n. 4, p. 41-50, 1985.

PETERS, T. J.; WATERMAN, R. H. Search of excellence: lessons from America's Best-Run Companies. Reprint ed. New York: HarperCollins, 2012.

<http://books.google.com.br/books?id=Cajl2dHa7SQC>. Acesso em: 16 out. 2013.

PONTIFICIA UNIVERSIDADE CATÓLICA DE SÃO PAULO. Comissão Própria de Avaliação. Autoavaliação Institucional da PUC-SP. São Paulo: [s.n.], 2012.

RAUPP, F. M.; BEUREN, I. M. Metodologia da pesquisa aplicável às Ciências Sociais. 3. ed. São Paulo: Atlas, 2006.

REA, L. M.; PARKER, R. A. Metodologia de pesquisa: do planejamento à execução. São Paulo: Pioneira, 2000.

RODRIGUES, A. M.; CASTRO, A. C.; SANTOS, E. B. Gestão em bibliotecas: um estudo realizado na associação recifense de ensino superior. Biblionline, v. 9, n. 1, p. 96-103, 2013.

SILVA, S. M. G. Qualidade nas bibliotecas universitárias: a influência dos objetivos. Informação \& Sociedade: Estudos, v. 10, n. 1, p. 1-9, 1 jan. 2000.

<http://www.okara.ufpb.br/ojs2/index.php/ies/article/view/342>. Acesso em: 28 fev. 2014.

STRAUSS, A.; CORBIN, J. Basics of qualitative research. London: Sage Publications, 2008. v. 3.

VANTI, N. Ambiente de qualidade em uma biblioteca universitária: aplicação do $5 S$ e de um estilo participativo de administração. Perspectivas em Ciência da Informação, v. 4, n. 2, p. 333-339, 1999. Disponível em: <http://portaldeperiodicos.eci.ufmg.br/index.php/pci/article/view/570>. Acesso em: 28 fev. 2014.

VERGUEIRO, W; CARVALHO, T. Definição de indicadores de qualidade: a visão dos administradores e clientes de bibliotecas universitárias. Perspectivas em Ciência da Informação, v. 6, n. 1, p. 27, 2001. Disponível em:

<http://portaldeperiodicos.eci.ufmg.br/index.php/pci/article/viewFile/435/ 245>. Acesso em: 28 fev. 2014.

ZEITHAML, V. A; PARASURAMAN, A.; BERRY, L. L. Delivering quality service: balancing customer perceptions and expectations. New York: Free Press, 1990. 